УДК 159.952-053.5

DOI https://doi.org/10.26661/2310-4368/2021-3-1

\title{
ПСИХОЛОГІЧНІ ОСОБЛИВОСТІ РОЗВИТКУ ВЛАСТИВОСТЕЙ УВАГИ в МОЛОДШИХ ШКОЛЯРІВ
}

\author{
Бушусва Т. В. \\ кандидат психологічних наук, дочент, \\ професор кафедри загальної і сочіальної психологї̈ та психотерапії \\ Національний педагогічний університет імені М. П. Драгоманова \\ вул. Пирогова, 9, Київ, Украӥна \\ orcid.org/0000-0002-7512-0037 \\ bushtv2017@ukr.net \\ Авер'янова А. М. \\ аспірант кафедри загальної і сочіальної психології та психотерапї \\ Національний педагогічний університет імені М. П. Драгоманова \\ вул. Пирогова, 9, Київ, Україна \\ orcid.org/0000-0002-2375-3350 \\ alina.averyanova@gmail.com
}

Ключові слова: увага,

властивості уваги, кониентрація, обсяг, стійкість, розподіл, перемикання уваги, розвиток, молодший шкільний вік.
У статті представлено аналіз результатів емпіричного дослідження психологічних особливостей властивостей уваги молодших школярів: вікових, індивідуальних, статевих. Для сучасних молодших школярів доступ до цифрових технологій і постійна взаємодія 3 інформаційним середовищем є звичними. Це зумовлює психологічні особливості дітей порівняно з їхніми ровесниками минулих поколінь. Відповідь на питання щодо особливостей розвитку уваги сучасних молодших школярів важлива як для науки, так і для практики організації освітнього процесу. Для дослідження рівня розвитку властивостей уваги дітей молодшого шкільного віку нами використовувалися такі методики: методика Мюнстерберга (визначення концентрації уваги); методика «Запам’ятай та розстав крапки» (визначення обсягу уваги), методика «Кільця Ландольта» (визначення стійкості, розподілу, перемикання уваги). Вибірка складалася 3239 учнів 1-4 класів навчальних закладів міста Києва. Показано, що розвиток властивостей уваги сучасних молодших школярів має нерівномірний характер: нерівномірність розвитку на різних етапах навчання та нерівномірність інтенсивності розвитку різних властивостей уваги. Найбільш інтенсивний розвиток властивостей уваги напочатковому етапі (перший-другий класи), менш інтенсивний на завершальному етапі (третій-четвертий класи) і найменш інтенсивний на етапі другий-третій класи. Серед властивостей уваги найбільш інтенсивного розвитку в молодшому шкільному віці зазнають концентрація, обсяг і перемикання уваги, найменш інтенсивного - стійкість і розподіл уваги. У молодшому шкільному віці діапазон індивідуальних відмінностей у розвитку концентрації, обсягу й перемикання уваги розширюється, а розподілу уваги не змінюється. Визначені кількісні та якісні зміни в структурі властивостей уваги молодших школярів. За результатами кореляційного аналізу, відбувається динаміка зв'язку між властивостями уваги на різних етапах навчання молодших школярів i зміна ознаки-індикатора, яка викликає «стягування» інших ознак у кореляційну плеяду. Провідними в структурі властивостей уваги першокласників $є$ стійкість уваги, другокласників - розподіл і стійкість уваги, четвертокласників - розподіл 
уваги. Визначений кращий розвиток концентрації та перемикання уваги в дівчат молодшого шкільного віку порівняно з хлопчиками. Значущих статевих відмінностей за показниками обсягу, стійкості, розподілу уваги в дітей молодшого шкільного віку не виявлено. Визначено, що основні особливості розвитку властивостей уваги сучасних молодших школярів полягають у тому, що провідними в структурі властивостей уваги $\epsilon$ стійкість і розподіл уваги, які зазнають найменш інтенсивних змін упродовж молодшого шкільного віку.

\title{
PSYCHOLOGICAL FEATURES OF THE DEVELOPMENT OF ATTENTION PROPERTIES IN JUNIOR SCHOOLCHILDREN
}

\author{
Bushueva T. V. \\ Candidate of Psychological Sciences, Associate Professor, \\ Professor at the Department of General and Social Psychology and Psychotherapy \\ National Pedagogical Dragomanov University, \\ Pirogova str., 9, Kyiv, Ukraine \\ orcid.org/0000-0002-7512-0037 \\ bushtv2017@ukr.net \\ Averyanova A. M. \\ Postgraduate Student at the Department of General \\ and Social Psychology and Psychotherapy \\ National Pedagogical Dragomanov University, \\ Pirogova str., 9, Kyiv, Ukraine \\ orcid.org/0000-0002-2375-3350 \\ alina.averyanova@gmail.com
}

Key words: attention, properties of attention, concentration, volume, stability, distribution, switching of attention, development, primary school age.
The article presents an analysis of the results of an empirical study of the psychological characteristics of the properties of attention of primary school children: age, individual, gender. For today's younger students, access to digital technologies and constant interaction with the information environment are common. This determines the psychological characteristics of children compared to their peers of past generations. The answer to the question about the peculiarities of the development of attention of modern junior schoolchildren is important both for science and for the practice of organizing the educational process. To study the level of development of attention properties of children of primary school age, we used the following methods: Munsterberg method (determination of concentration); "Remember and dot" method (determination of the amount of attention), "Landolt's rings" method (determination of stability, distribution, switching of attention). The sample consisted of 239 students of grades 1-4 of educational institutions of the city of Kyiv. It is shown that the development of the properties of attention of modern junior schoolchildren has a non-uniform character: uneven development at different stages of learning and uneven intensity of development of different properties of attention. The most intensive development of the properties of attention at the initial stage (first-second grades), less intensive at the final stage (third-fourth grades) and the least intensive at the stage of second-third grades. Among the properties of attention of the most intensive development in primary school age are concentration, volume and switching of attention, the least intensive - stability and distribution of attention. In early school age, the range of individual differences in the development of concentration, 
volume and switching of attention expands, and the distribution of attention does not change. Quantitative and qualitative changes in the structure of attention properties of junior schoolchildren are determined. According to the results of correlation analysis, there is a dynamics of the relationship between the properties of attention at different stages of learning of younger students and the change of the indicator sign, which causes the "contraction" of other features in the correlation galaxy. Leading in the structure of the properties of attention of first-graders are the stability of attention, second-graders the distribution and stability of attention, fourth-graders - the distribution of attention. The best development of concentration and switching of attention at girls of primary school age in comparison with boys is defined. Significant gender differences in terms of volume, stability, distribution of attention in children of primary school age were not detected. It is determined that the main features of the development of attention properties of modern primary school students are that the leading in the structure of attention properties are stability and distribution of attention, which undergo the least intensive changes during primary school age.

Постановка проблеми. На сучасному етапі розвитку освіти актуальною стає проблема розвитку уваги дітей молодшого шкільного віку, які якісно відрізняються від своїх однолітків попередніх поколінь за фізіологічними та психологічними особливостями. Ресурси уваги допомагають орієнтуватися в широкому інформаційному середовищі й активно переробляти інформацію. Від розвитку й організації уваги молодших школярів залежать якість та успішність сприймання, засвоєння й розуміння навчального матеріалу. Для сучасних молодших школярів доступ до цифрових технологій і постійна взаємодія 3 інформаційним середовищем є звичними. Навчання та застосування інформаційних технологій у початковій школі має відбуватися на основі врахування вікових та індивідуальних особливостей розвитку уваги сучасних молодших школярів. У чому особливості розвитку уваги сучасних молодших школярів? Відповідь на це питання важлива як для науки, так і для практики організації освітнього процесу.

Незважаючи на доволі широке вивчення проблематики уваги, сьогодні немає єдиного визначення цього поняття. У вітчизняній психології увага традиційно розглядається як спрямованість і зосередженість психічної діяльності [1]. Спрямованість полягає у виборі певного виду діяльності, а зосередженість - у підтриманні вибору та заглибленні в діяльність. Таке визначення уваги характеризує селективний і ресурсний аспекти уваги, які активно вивчалися в когнітивній психології. У конструктивній теоpiї У. Найссера увага представлена як механізм активного процесу побудови перцептивного образу. Увага як вибірковість сприймання залежить від активності суб'єкта, розвитку перцептивних схем - умінь і навичок збору інформації
[2]. Увага як розумове зусилля розглядається в ресурсній моделі уваги Д. Канемана. Ефективність уваги залежить від складності завдання та розподілу ресурсів уваги [3]. Для обгрунтування цієї моделі К. Сидоров уводить поняття «потужність уваги». Потужність уваги вимірює ресурс уваги суб'єкта та є індикатором ефективності виконання діяльності [4].

Увага характеризується властивостями, які систематизуються залежно від того, спрямована увага на один об'єкт або декілька: 1) до властивостей, що характеризують увагу, спрямовану на один об'єкт, відносять концентрацію, обсяг, стійкість; 2) до властивостей, що характеризують увагу, спрямовану на декілька об'єктів, відносять розподіл і перемикання.

Аналіз останніх досліджень і публікацій. Результати емпіричних досліджень констатують невисокі показники розвитку властивостей уваги молодших школярів. В. Долгова, О. Кондратьєва, М. Скирдова зазначають, що увага дітей молодшого шкільного віку характеризується малою стійкістю, невеликим обсягом, низьким рівнем розподілу та перемикання [5]. За результатами дослідження Т. Гетьман, молодші школярі мають переважно низький рівень стійкості й концентрації уваги [6]. І. Вишнівська, Н. Свдокимова виявили в більшості досліджуваних учнів 1-4 класів середній рівень розвитку концентрації та обсягу уваги [7]. У дослідженні П. Сабаніна показано, що в більшості дітей 9-10 років обсяг уваги розвинений на середньому рівні, а концентрація уваги розвинена слабо [8]. K. Almakhan, K. Manshuk виявили, що стійкість уваги в молодших школярів динамічно розвивається від середніх значень до високих, перемикання уваги - від низьких значень до середніх, щорічно зростає здатність до розподілу уваги [9]. 
У дослідженні О. Дніпрової (на замалій вибірці $\mathrm{n}=26$ ) визначено такі статеві особливості розвитку властивостей уваги молодших школярів: у хлопчиків концентрація уваги розвинена більше, а обсяг уваги - менше, ніж у дівчат; рівень розвитку розподілу та перемикання уваги майже однаковий [10]. I. Захарова констатує відсутність різниці рівня розвитку концентрації, стійкості, перемикання уваги хлопчиків і дівчат молодшого шкільного віку [11].

Необхідно зазначити складність порівняння результатів різних досліджень унаслідок відмінностей у вибірках (як якісних (вікових, статевих), так і кількісних) і методиках визначення властивостей уваги, які використовували різні дослідники. Однак у цілому дослідження розвитку уваги сучасних молодших школярів надають суперечливі результати щодо розвитку властивостей уваги.

Мета дослідження - емпірично визначити психологічні особливості властивостей уваги в дітей молодшого шкільного віку.

Завдання дослідження: 1) визначити наукові підходи до розробки проблеми уваги та ії розвитку; 2) емпірично виявити динаміку розвитку властивостей уваги в молодших школярів на різних етапах навчання; 3) визначити індивідуальні та статеві особливості розвитку властивостей уваги молодших школярів.

Для емпіричної оцінки рівня розвитку властивостей уваги дітей молодшого шкільного віку використовувалися такі методики: методика Мюнстерберга (оскільки навчання відбувається на базі мови, для дослідження розвитку концентрації уваги учнів нами обрана методика, яка передбачає роботу дітей із вербальним стимульним матеріа- лом); методика «Запам'ятай та розстав крапки» (визначення обсягу уваги), методика «Кільця Ландольта» (визначення стійкості, розподілу, перемикання уваги).

Емпіричне дослідження проводилося впродовж 2019-2020 років на базі загальноосвітньої школи № 286 і навчально-виховного комплексу «Міжнародний ліцей МАУП» міста Києва. Дослідження охопило 239 учнів молодшого шкільного віку: учнів 1 класу - 64 особи (34 хлопчики, 30 дівчат), учнів 2 класу - 58 осіб (34 хлопчики, 24 дівчат), учнів 3 класу - 61 особа (33 хлопчики, 28 дівчат), учнів 4 класу - 56 осіб (26 хлопчиків, 30 дівчат).

Виклад основного матеріалу дослідження. Узагальнені результати визначення рівня розвитку властивостей уваги в досліджуваної вибірки молодших школярів подано в таблиці 1.

Згідно 3 отриманими результатами, рівень розвитку концентрації уваги більшості досліджуваних $(58,1 \%) \epsilon$ високим або дуже високим. Разом із тим у $29,6 \%$ молодших школярів рівень концентрації уваги низький або дуже низький. За рівнем розвитку обсягу уваги досліджувані розподілилися так: 44,8\% мають високий або дуже високий рівень розвитку обсягу уваги, а $41,9 \%$ - низький або дуже низький рівень. Отримані результати свідчать також про переважання середнього рівня розвитку стійкості й перемикання уваги, низького рівня розвитку розподілу уваги в дітей молодшого шкільного віку.

Наступним завданням дослідження було вивчення динаміки розвитку властивостей уваги в молодших школярів 3 першого по четвертий клас навчання. За середніми значеннями показників (див. таблицю 2) в учнів першого класу визначається низький рівень розвитку концентрації, обсягу, розподілу, перемикання уваги та середній

Таблиця 1

Рівні розвитку властивостей уваги дітей молодшого шкільного віку (у\%) n=239

\begin{tabular}{|l|c|c|c|c|c|}
\hline \multirow{2}{*}{ Рівні розвитку } & \multicolumn{5}{|c|}{ Властивості уваги } \\
\cline { 2 - 6 } & концентрація & обсяг & стійкість & розподіл & перемикання \\
\hline Дуже високий & 46,4 & 27,6 & 2,1 & - & 1,7 \\
\hline Високий & 11,7 & 17,2 & 9,6 & - & 5,4 \\
\hline Середній & 12,6 & 13,0 & 66,1 & 7,9 & 56,9 \\
\hline Низький & 17,0 & 16,0 & 19,0 & 61,0 & 29,0 \\
\hline Дуже низький & 12,6 & 25,9 & 3,3 & 31,0 & 7,1 \\
\hline
\end{tabular}

Таблиця 2

Динаміка розвитку властивостей уваги в дітей молодшого шкільного віку

\begin{tabular}{|c|c|c|c|c|c|}
\hline \multirow{2}{*}{ Період навчанняя Властивості уваги } \\
\cline { 2 - 6 } & концентрація & обсяг & стійкість & розподіл & перемикання \\
\cline { 2 - 6 } & $\mathbf{M} \pm \boldsymbol{\sigma}$ & $\mathbf{M} \pm \boldsymbol{\sigma}$ & $\mathbf{M} \pm \boldsymbol{\sigma}$ & $\mathbf{M} \pm \boldsymbol{\sigma}$ & $\mathbf{M} \pm \boldsymbol{\sigma}$ \\
\hline 1 клас (n=64) & $3,42 \pm 2,23$ & $2,53 \pm 0,76$ & $0,48 \pm 0,17$ & $0,22 \pm 0,11$ & $0,39 \pm 0,16$ \\
\hline 2 клас (n=58) & $8,10 \pm 4,22$ & $4,34 \pm 1,85$ & $0,63 \pm 0,19$ & $0,29 \pm 0,10$ & $0,57 \pm 0,15$ \\
\hline 3 клас (n=61) & $10,15 \pm 4,68$ & $4,79 \pm 2,27$ & $0,76 \pm 0,20$ & $0,31 \pm 0,11$ & $0,67 \pm 0,21$ \\
\hline 4 клас (n=56) & $12,95 \pm 4,38$ & $5,79 \pm 1,47$ & $0,90 \pm 0,21$ & $0,41 \pm 0,11$ & $0,84 \pm 0,30$ \\
\hline
\end{tabular}


рівень розвитку стійкості уваги. У учнів другого класу показники концентрації та стійкості уваги зростають до високого рівня розвитку; показники обсягу й перемикання уваги - до середнього рівня розвитку; розподіл уваги залишається на низькому рівні розвитку. В учнів третього класу концентрація уваги досягає дуже високого рівня розвитку, а обсяг, стійкість і перемикання уваги - високого рівня розвитку. При цьому розподіл уваги залишається на низькому рівні розвитку. В учнів четвертого класу виявлено дуже високий рівень розвитку концентрації, обсягу, стійкості й перемикання уваги. Розподіл уваги четвертокласників досягає середнього рівня розвитку.

Згідно $з$ отриманими результатами, найбільш інтенсивного розвитку в молодшому шкільному віці зазнає концентрація уваги. Середні показники концентрації уваги в четвертокласників у 3,8 рази вищі, ніж у першокласників. Середні показники обсягу уваги учнів четвертого класу у 2,3 рази вищі, ніж в учнів першого класу, а середні показники перемикання уваги вищі у 2,2 рази. Найменш інтенсивних змін зазнають стійкість і розподіл уваги: середні їх показники в учнів четвертого класу в 1,9 рази більші, ніж у першокласників.

Оскільки стійкість і розподіл уваги визначені як властивості, які найменш інтенсивно розвиваються в молодшому шкільному віці, їх динаміка вивчалася докладніше. Розглядалася динаміка показників швидкості переробки інформації та точності роботи, які визначаються за методикою «Кільця Ландольта». Виявлене поступове зростання показників швидкості при оцінці стійкості уваги учнів на всіх етапах навчання $(p \leq 0,001)$. Показники точності роботи передбачали врахування помилок двох типів: пропуск символу та неправильно закреслений символ. Кількість помилок пропуску символу при оцінці стійкості уваги учнів різних класів збільшується (1 клас: $\mathrm{M} \pm \sigma=1,55 \pm 2,36$; 4 клас: $M \pm \sigma=3,95 \pm 4,28)$, кількість помилкового закреслення символу зменшується (1 клас: $\mathrm{M} \pm \sigma=3,11 \pm 7,66 ; 4$ клас: $\mathrm{M} \pm \sigma=0,09 \pm 0,35)$, усереднені показники точності роботи в оцінці стійкості уваги учнів на різних етапах навчання статистично значущо не розрізняються $(p>0,05)$. Показники швидкості при оцінці розподілу уваги учнів зростають на етапі перший-другий класи $(p=0,01)$, значущо не змінюються на етапі другий-третій класи $(\mathrm{p}>0,05)$ і знову зростають на етапі третій-четвертий класи $(p<0,001)$. Кількість помилок пропуску символу при оцінці розподілу уваги учнів різних класів збільшується (1 клас: $\mathrm{M} \pm \sigma=7,34 \pm 5,14 ; 4$ клас: $\mathrm{M} \pm \sigma=9,27 \pm 7,27)$, кількість помилкового закреслення символу зменшується ( 1 клас: $\mathrm{M} \pm \sigma=3,80 \pm 6,46 ; 4$ клас: $\mathrm{M} \pm \sigma=1,34 \pm 7,00)$, усереднені показники точ- ності роботи в оцінці розподілу уваги учнів на різних етапах навчання статистично значущо не різняться $(\mathrm{p}>0,05)$. Отже, зростання показників стійкості й розподілу уваги молодших школярів відбувається за рахунок зростання швидкості переробки інформації при сталих показниках точності роботи.

Показники концентрації, обсягу та перемикання уваги молодших школярів мають найбільшу індивідуальну варіативність порівняно 3 іншими властивостями уваги. Кількісні значення $\sigma$ (як міри варіативності ознаки) у показників концентрації, обсягу та перемикання уваги збільшуються майже вдвічі в четвертокласників порівняно $з$ учнями першого класу. Найменша варіативність властива показникам розподілу уваги учнів, і вона $є$ сталою на різних етапах навчання молодших школярів. Отже, у молодшому шкільному віці діапазон індивідуальних відмінностей у розвитку концентрації, обсягу та перемикання уваги розширюється. Тож учителям необхідно враховувати, що індивідуальні відмінності в розвитку цих властивостей уваги в учнів четвертого класу значно перевищують ті, що мають першокласники.

Розвиток властивостей уваги в дітей молодшого шкільного віку має нерівномірний характер. Найбільш інтенсивний розвиток концентрації, обсягу, стійкості, перемикання уваги відбувається на етапі першого-другого класу. Відмінності в рівні розвитку властивостей уваги першокласників і другокласників є статистично значущими $(\mathrm{p}<0,001)$. На етапі другий-третій класи менш інтенсивний розвиток властивостей уваги. Виявлені статистично значущі відмінності в рівні розвитку концентрації ( $\mathrm{p}=0,01)$, стійкості $(\mathrm{p}<0,001)$ i перемикання $(\mathrm{p}<0,01)$ уваги учнів другого та третього класів. Статистично значущих відмінностей між показниками обсягу та розподілу уваги цих учнів не виявлено $(\mathrm{p}>0,05)$. На етапі третій-четвертий класи в розвитку властивостей уваги відбуваються зміни, але не такі інтенсивні, як на початковому етапі (перший-другий класи). Виявлені статистично значущі відмінності в показниках концентрації $(\mathrm{p}=0,001)$, обсягу $(\mathrm{p}<0,01)$, стійкості $(\mathrm{p}<0,001)$, розподілу $(\mathrm{p}<0,001)$ і перемикання $(\mathrm{p}<0,001)$ уваги в молодших школярів третього та четвертого класів. Отже, найбільш інтенсивний розвиток властивостей уваги на початковому етапі (перший-другий класи), менш інтенсивний на завершальному етапі (третій-четвертий класи) і найменш інтенсивний на етапі другий-третій класи.

Для дослідження динаміки зв'язку між властивостями уваги на різних етапах навчання молодших школярів проведено кореляційний аналіз. 
Таблиця 3

Значущі коефіціснти кореляції Пірсона показників властивостей уваги учнів першого класу $(\mathrm{n}=64)$

\begin{tabular}{|l|c|c|c|c|c|}
\hline Властивості уваги & Концентрація & Обсяг & Стійкість & Розподіл & Перемикання \\
\hline Концентрація & - & & $0,471^{* * *}$ & $0,379 * *$ & $0,319^{* *}$ \\
\hline Обсяг & & - & $0,263 *$ & & $0,261^{*}$ \\
\hline Стійкість & $0,471^{* * *}$ & $0,263 *$ & - & $0,404 * * *$ & $0,659^{* * *}$ \\
\hline Розподіл & $0,379^{* *}$ & & $0,404 * * *$ & - & \\
\hline Перемикання & $0,319^{* *}$ & $0,261^{*}$ & $0,659 * * *$ & & - \\
\hline
\end{tabular}

Примітка: * $\mathrm{p}<0,05 ; * * \mathrm{p}<0,01 ; * * * \mathrm{p}<0,001$.

Відповідно до інтерпретації кореляційної матриці, член кореляційної плеяди, який має найбільшу кількість зв'язків 3 іншими членами, визначається як «ознака-індикатор», яка викликає «стягування» інших властивостей у плеяду. Ознакою-індикатором, тобто провідною в структурі властивостей уваги першокласників, є стійкість уваги, яка має значущі зв'язки з усіма іншими властивостями.

Згідно 3 отриманими результатами, провідними в структурі властивостей уваги учнів другого класу є розподіл і стійкість уваги. Розподіл уваги має значущі зв'язки зі стійкістю ( $\mathrm{r}=0,502$, $\mathrm{p}=0,000) ;$ перемиканням $(\mathrm{r}=0,379, \quad \mathrm{p}=0,003)$; обсягом уваги $(\mathrm{r}=0,371, \mathrm{p}=0,004)$. Стійкість уваги в другокласників пов'язана також із перемиканням $(\mathrm{r}=0,306, \mathrm{p}=0,020)$ та концентрацією уваги $(\mathrm{r}=0,296, \mathrm{p}=0,024)$. При цьому концентрація уваги не має значущих зв'язків 3 іншими властивостями уваги учнів другого класу.
Кореляційна матриця показників властивостей уваги учнів третього класу містить лише значущі зв'язки між стійкістю, розподілом і перемиканням уваги. Концентрація й обсяг уваги не мають значущих зв'язків 3 іншими властивостями уваги третьокласників.

Провідною властивістю в структурі властивостей уваги учнів четвертого класу є розподіл уваги, що має значущі зв'язки $з$ усіма іншими властивостями. Крім зміни ознаки-індикатора, у кореляційній матриці показників властивостей уваги четвертокласників порівняно 3 першокласниками фіксується ще одна відмінність: обсяг уваги має значущий зв'язок тільки $з$ розподілом уваги.

Дослідження особливостей розвитку властивостей уваги в хлопчиків і дівчат молодшого шкільного віку дало змогу визначити таке (див. таблицю 5).

Виявлено статистично значущі відмінності показників концентрації та перемикання уваги

Таблиця 4

Значущі коефіціснти кореляції Пірсона показників властивостей уваги учнів четвертого класу $(\mathbf{n}=56)$

\begin{tabular}{|l|c|c|c|c|c|}
\hline \multicolumn{1}{|c|}{ Властивості уваги } & Концентрація & Обсяг & Стійкість & Розподіл & Перемикання \\
\hline Концентрація & - & & $0,355^{* *}$ & $0,414^{* *}$ & $0,367^{* *}$ \\
\hline Обсяг & & - & & $0,403^{* *}$ & \\
\hline Стійкість & $0,355^{* *}$ & & - & $0,522^{* * *}$ & $0,677^{* * *}$ \\
\hline Розподіл & $0,414^{* *}$ & $0,403^{* *}$ & $0,522^{* * *}$ & - & $0,615^{* * *}$ \\
\hline Перемикання & $0,367^{* *}$ & & $0,677^{* * *}$ & $0,615^{* * *}$ & - \\
\hline
\end{tabular}

Примітка: * $\mathrm{p}<0,05 ; * * \mathrm{p}<0,01 ; * * * \mathrm{p}<0,001$.

Таблиця 5

Середні значення показників властивостей уваги в хлопчиків і дівчат молодшого шкільного віку

\begin{tabular}{|c|c|c|c|c|}
\hline \multirow{2}{*}{ Властивості уваги } & $\begin{array}{c}\text { Хлопчики } \\
\mathbf{( n = 1 2 7 )}\end{array}$ & $\begin{array}{c}\text { Дівчата } \\
\mathbf{( n = 1 1 2 )}\end{array}$ & $\begin{array}{c}\text { Критерій } \\
\text { Стьюдента }\end{array}$ & $\begin{array}{c}\text { Рівень значу- } \\
\text { щості }\end{array}$ \\
\cline { 1 - 4 } & $\mathbf{M} \pm \boldsymbol{\sigma}$ & $\mathbf{M} \pm \boldsymbol{\sigma}$ & $\mathbf{t}$ & $\mathbf{p}$ \\
\hline Концентрація & $7,84 \pm 4,76$ & $9,26 \pm 5,76$ & $-2,053$ & $\mathrm{p}<0,05$ \\
\hline Обсяг & $4,42 \pm 2,08$ & $4,19 \pm 2,01$ & 0,866 & $\mathrm{p}>0,05$ \\
\hline Стійкість & $0,66 \pm 0,22$ & $0,71 \pm 0,26$ & $-1,319$ & $\mathrm{p}>0,05$ \\
\hline Розподіл & $0,29 \pm 0,12$ & $0,32 \pm 0,13$ & $-1,854$ & $\mathrm{p}>0,05$ \\
\hline Перемикання & $0,57 \pm 0,23$ & $0,65 \pm 0,30$ & $-2,359$ & $\mathrm{p}<0,05$ \\
\hline
\end{tabular}


хлопчиків i дівчат молодшого шкільного віку $(\mathrm{p}<0,05)$. У дівчат ці властивості уваги мають вищий рівень розвитку. При цьому індивідуальна варіативність показників концентрації та перемикання уваги дівчат більша, ніж у хлопців. Значущих статевих відмінностей за показниками обсягу, стійкості, розподілу уваги в дітей молодшого шкільного віку не виявлено.

Висновки. Проведене емпіричне дослідження дало змогу визначити вікові, індивідуальні та статеві особливості розвитку властивостей уваги в сучасних молодших школярів.

За середніми значеннями показників у першокласників концентрація, обсяг, розподіл і перемикання уваги мають низький рівень розвитку, а стійкість уваги - середній рівень. У кінці навчання в початковій школі розвиток концентрації, обсягу, стійкості й перемикання уваги учнів набуває дуже високого рівня, а розподілу уваги - середнього рівня. Розвиток властивостей уваги молодших школярів нерівномірний на різних етапах навчання. Інтенсивний розвиток властивостей уваги на початковому етапі (перший-другий класи) змінюється уповільненням розвитку на етапі другий-третій класи, а на завершальному етапі (третій-четвертий класи) інтенсивність розвитку знову зростає. Також нерівномірна інтенсивність розвитку різних властивостей уваги молодших школярів. Найбільш інтенсивного розвитку в молодшому шкільному віці зазнає концентрація уваги, найменш інтенсивного - стійкість і розподіл уваги. Зростання показників стійкості й розподілу уваги відбувається за рахунок зростання швидкості переробки інформації при сталих показниках точності роботи. Дослідження динаміки зв'язку між властивостями уваги на різних етапах навчання молодших школярів виявило, що провідними в структурі властивостей уваги першокласників $є$ стійкість уваги, другокласників - розподіл і стійкість уваги, четвертокласників - розподіл уваги. Отже, провідними в структурі властивостей уваги молодших школярів $\epsilon$ стійкість і розподіл уваги.

У молодшому шкільному віці діапазон індивідуальних відмінностей у розвитку концентрації, обсягу та перемикання уваги розширюється. Діапазон індивідуальних відмінностей у розвитку розподілу уваги на різних етапах навчання молодших школярів не змінюється.

Визначено кращий розвиток концентрації та перемикання уваги в дівчат молодшого шкільного віку порівняно 3 хлопчиками. При цьому індивідуальна варіативність показників концентрації та перемикання уваги дівчат більша, ніж у хлопців. Значущих статевих відмінностей за показниками обсягу, стійкості, розподілу уваги в молодших школярів не виявлено.

Перспективи подальших досліджень убачаємо у вивченні зв'язку властивостей уваги і когнітивних стилів дітей молодшого шкільного віку.

\section{ЛІТЕРАТУРА}

1. Гиппенрейтер Ю.Б., Романов В.Я. (ред.). Психология внимания. Москва : АСТ: Астрель, 2008.

2. Найссер У. Познание и реальность. Смысл и принципы когнитивной психологи / пер. англ. В. Лучкова. Москва : Прогресс, 1981.

3. Канеман Д. Внимание и усилие / пер. англ. И. Уточкин. Москва : Смысл, 2006.

4. Сидоров К.Р., Михайлова В.В. Показатель «мощность внимания» и его прогностические возможности. Вестник Удмуртского университета. Серия «Философия. Психология. Педагогика». 2014. Вып. 3. С. 43-49.

5. Долгова В.И., Кондратьева О.А., Скирдова М.Н. Изучение влияния свойств внимания на успеваемость младших школьников. Концеnт. 2015. Т. 31. С. 106-110. URL: http://e-koncept.ru/2015/95528.htm

6. Гетьман Т.О. Врахування індивідуальних особливостей уваги молодших школярів у навчальному процесі. Міжнародний науковий форум: соиіологія, психологія, педагогіка, менеджмент. 2012. № 8. C. 2004-2012.

7. Вишнівська І.О., Свдокимова Н.О. Розвиток та корекція уваги учнів молодшого шкільного віку. Парадигма пізнання. 2015. № 3 (6). URL: https://naukajournal.org/index.php/Paradigm/article/view/479

8. Сабанин П.В. Роль произвольного внимания в умственной деятельности младшего школьника. Наука. Мысль. 2014. № 7. URL: wwenews.esrae.ru/17-488

9. Almakhan K., Manshuk K. Primary School Children Cognitive Processes Development Research. Creative Education. 2014. № 5. P. 155-163. URL: http://dx.doi.org/10.4236/ce.2014.54024

10. Дніпрова О.А. Дослідження уваги хлопчиків та дівчат молодшого шкільного віку. Вісник Дніпропетровського університету імені Альфреда Нобеля. Серія «Педагогічні науки». 2015. Вип. 2 (10). С. 91-96.

11. Захарова И.Н. Особенности свойств внимания: концентрация, устойчивость и переключаемость у младших школьников. Молодой ученый. 2018. № 49 (235). С. 272-275. URL: https://moluch.ru/ archive $/ 235 / 54570$ 


\section{REFERENCES}

1. Gippenreyter Yu.B., Romanov V.Ya. (Red.) (2008). Psihologiya vnimaniya. [Attention psychology]. Moskva : AST: Astrel [in Russian].

2. Naysser U. Per. angl. Luchkova V. (1981). [Poznanie i realnost. Smyisl i printsipyi kognitivnoy psihologii. [Cognition and Reality. The meaning and principles of cognitive psychology]. Moskva : Progress [in Russian].

3. Kaneman D. Per. angl. Utochkin I (2006). Vnimanie i usilie. [Vnimanie i usilie]. Moskva : Smyisl [in Russian].

4. Sidorov K.R., Mihaylova V.V. (2014). Pokazatel «moschnost vnimaniya» i ego prognosticheskie vozmozhnosti. [The indicator «power of attention» and its predictive capabilities]. Vestnik Udmurtskogo universiteta. Seriya Filosofiya. Psihologiya. Pedagogika», Vyip. 3, pp. 43-49 [in Russian].

5. Dolgova, V.I., Kondrateva, O.A., Skirdova, M.N. (2015). Izuchenie vliyaniya svoystv vnimaniya na uspevaemost mladshih shkolnikov [Study of the influence of the properties of attention on the performance of primary schoolchildren]. Nauchno-metodicheskiy elektronnyiy zhurnal «Kontsept». Retrieved from https://e-koncept.ru/2015/95528.htm [in Russian].

6. Het'man, T.O. (2012). Vrakhuvannia indyvidual'nykh osoblyvostej uvahy molodshykh shkoliariv u navchal'nomu protsesi [Taking into account the individual characteristics of the attention of younger students in the learning process]. Mizhnarodnyj naukovyj forum: sotsiolohiia, psykholohiia, pedahohika, menedzhment. Kyiv. Vypusk 8, pp. 204-212 [in Ukrainian].

7. Vyshnivs'ka, I.O., Yevdokymova, N.O. (2015). Rozvytok ta korektsiia uvahy uchniv molodshoho shkil'noho viku [Development and correction of attention of primary school students]. Paradyhma piznannia: Humanitarni pytannia, 3(6). Retrieved from https://naukajournal.org/index.php/Paradigm/article/ view/479/657 [in Ukrainian].

8. Sabanin, P.V. (2014). Rol proizvolnogo vnimaniya v umstvennoy deyatelnosti mladshego shkolnika [The role of voluntary attention in the mental activity of a younger student]. Nauka. Myisl. Retrieved from http://wwenews.esrae.ru/17-488 [in Russian].

9. Kabylova Almakhan, Kussainova Manshuk (2014). Primary School Children Cognitive Processes Development Research. Creative Education, 5, 155-163. Retrieved from http://dx.doi.org/10.4236/ce.2014.54024 [in English].

10. Dniprova, O.A. (2015). Doslidzhennia uvahy khlopchykiv ta divchat molodshoho shkil'noho viku. [A study of the attention of boys and girls of primary school age]. Visnyk Dnipropetrovs'koho universytetu imeni Al'freda Nobelia. 2 (10), 91-96 [in Ukrainian].

11. Zaharova I.N. (2018). Osobennosti svoystv vnimaniya: kontsentratsiya, ustoychivost i pereklyuchaemost $\mathrm{u}$ mladshih shkolnikov. [Features of the properties of attention: concentration, stability and switchability in younger students]. Molodoy uchenyiy, 49 (235), pp. 272-275. Retrieved from https://moluch.ru/ archive/235/54570 [in Russian]. 